\title{
1 A DISCRIMINANT MODEL FOR MEASURING COMPETITION INTENSITY OF 2 CONSTRUCTION MARKET
}

Kunhui $\mathrm{YE}^{1^{*}}$, Liyin SHEN ${ }^{2}$, and Weisheng $\mathrm{LU}^{3}$

1-Kunhui YE, Ph.D (corresponding author)

Associate Professor, Faculty of Construction Management and Real Estate, Chongqing University, Chongqing, China. Email: Kunhui.YE@Gmail.com

2 - Liyin SHEN, Ph.D

Professor, Director of International Research Center for Sustainable Built Environment, Chongqing University, Chongqing, China. Email: Shenliyin@cqu.edu.cn

3 - Weisheng LU

Assistant Professor, Department of Real Estate and Construction, The University of Hong Kong, Pokfulam, Hong Kong, Email: wilsonlu@hku.hk

\section{ABSTRACT}

"Competition intensity" is a factor in addressing competitiveness. The understanding on competition intensity is prerequisite to the formulation of industrial competition policies as well as firms' competition strategies. In the construction context, whereas competition intensity can be measured using a number of traditional approaches (e.g., competitor number, concentration), the measurement is often criticized for poor efficiency. This study proposes a new model for measuring competition intensity in light of the theory of discriminant analysis. The proposed model is composed of predictor variables concerned with market operation as well as criterion variables that classify markets into a few predefined groups based on the values of competition intensity. Empirical data of China's local construction markets were collected to verify the proposed model. The research findings indicate that the model can offset the drawbacks of traditional measures in the construction market. It is recommended using the proposed 
30 model to predict the competition trend of construction market especially when data for the traditional

31 approaches are poor or not readily available.

\section{KETWORDS}

34 Market competitiveness, construction competition, concentration, multivariate discriminant analysis, 35 China

\section{INTRODUCTION}

39 Competing for survival is an ongoing fact of life for business to operate in an industrial context. The

40 selection rule of competition drives firms to orient business to the external changing market situations,

41 and it has been accepted as a cornerstone of market operation (Greer 1992). Therefore, properly

42 measuring and predicting the intensity of competition are foremost and paramount tasks to undertake in

43 the formulation of both industrial competition policies and competition strategies. According to Porter

44 (1980), there are five market forces that can determine competition intensity in a collective way, namely

45 the threat of substitute products, the threat of established rivals, the threat of new entrants, the bargaining

46 power of suppliers, and the bargaining power of customers. Subject to the combined effect of these forces,

47 the measurement of competition intensity is daunting. One of the primary reasons is that some of the

48 forces may exert overwhelming influence on business competition in a market, while others may not.

50 The measurement of competition intensity in construction enables governmental authorities to gauge

51 market operating efficiency, and helps contractors manage organizational competitiveness. On one hand, 52 industrial policies such as antitrust laws, privatization and deregulation imply that market 
53 competitiveness has no root in a monopoly situation. On the other hand, market players are reluctant to

54 confront themselves with over competition. This is the case in the construction industry. Construction

55 business competition normally refers to contractors' bidding activities (Kim and Reinschmidt 2006). The

56 lowest-price bidding mechanism widely adopted by clients has created an all-pervading competition

57 atmosphere in the construction market (Gruneberg and Ive 2000). However, clients are often blamed for

58 inviting too many contractors to bid for construction contracts simultaneously (Fu et al. 2003; Flanagan

59 and Norman 1985). Over competition, as a consequence, shrinks business profitability and jeopardizes

60 project performance with respect to schedule, cost, quality and environment (Sturts and Griffis, 2005).

61 Therefore, competition intensity stays at the core of construction competitiveness and previous studies

62 have elaborated it at two levels - project and market (Ye et al. 2008).

63

64 Measurement of competition intensity at the project level

65

66 The measurement of competition intensity at the project level presents the extent to which competition

67 happens in a pool of contractors who are bidding for common construction works. The measurement

68 facilitates decision-making on "bid or not to bid" (Wang et al. 2009; Lo et al. 2007). The larger the

69 number of competitors, the higher the level of competition intensity, and the lower the bid will be. Thus,

70 the indicator of competitor number has been used as a proxy for the intensity of competition to aid

71 construction business in understanding bidding practices. For instance, Ngai et al. (2002) recommended

72 clients to adopt different strategies by changing the number of invited bidders from one market situation

73 to another to ascertain that a certain intensity of competition can be derived. Ye et al. (2008) presented a

74 competitor number - based concept of project competition intensity that is favorable for clients to screen

75 out qualified contractors. 
77 Implicitly embedded in this type of measurement is an assumption of two extreme competition scenarios

78 (Greer 1992). One refers to perfect competition, of which the market is populated with numerous 79 homogenous firms. The other is monopoly wherein the market is dominated by very few firms. The 80 discrepancy between these two competition scenarios offers the rationale for that researchers often

81 employ competitor number to quantify competition intensity at the project level. However, simply using 82 the number of competitors to measure project competition intensity is inadequate. First, this indicator 83 mirrors only a part of rivalry without taking into account market forces other than the incumbent. Second, 84 it pays little attention to any potentially uneven distribution of market powers between existing 85 competitors, which could be a consequence of business competition over a period of time (Newcombe 86 1990). Third, a switch from quantity competition to price competition increases the intensity of 87 competition with a decrease in firm number in the meanwhile (Aghion et al. 2001), suggesting that the 88 intensity cannot always be measured quantitatively by the number of competitors. Therefore, the 89 measurement of competition intensity at the project level is of limitations.

91 Measuring competition intensity at the market level

93 Competition intensity at this level has been measured in a number of ways typically including 94 concentration (Ye et al. 2009), which is a useful instrument that quantifies the extent to which market 95 shares are distributed among incumbents (Bajo and Salas, 2002). There are two types of concentration 96 measures, relative and absolute, that measure the extent to which a market departs from a predefined 97 competition status (Fedderke and Szalontai 2009). The concentration ratio $\left(C R_{n}\right)$, where $n$ can be $4,8,12$, 98 etc. is relative, while the Lerner index (Lerner 1934), the Herfindahl-Hirschman index (Kilpatrick 1967), 
99 Entropy (Hart 1971), and the Lorenz curve (Bishop et al. 2003) are absolute. The relative measures are 100 derivable as they place the measurement on a small number of competitors and impose little requirement 101 on the data collection. The absolute approaches have the advantage of imaging a whole scope of business 102 competition in a market, but it depends on the availability of data for all businesses. In reverse, the lack 103 or incompleteness of quality data can give rise to erroneous judgments on market competition situations.

105 For the reason of poor data in the construction industry (Ruddock, 2002), the measurement of 106 competition intensity in the construction market has relied on relative concentration approaches (Ye et al. 107 2009). The studies by both Chiang et al. (2001) and Wang (2004) demonstrated that the relative 108 approaches are conducive to the identification of the characteristics of construction market. Yang et al. 109 (2012) found that the increasing market concentration in the construction market of Jiangsu of China has 110 a negative effect on the survival of construction companies. In a same vein, Ye et al. (2009) revealed a 111 moderate degree of competition in the international construction market. Nevertheless, the moderate 112 competition is a result from the assumption that the population of the international construction industry 113 is composed of the largest 225 contractors listed in Engineering News-Record. In reality, these 225 114 contractors only represent a small part of the entire industry. It appears nevertheless that researchers 115 spared no effort in searching for alternatives to address the problem where data are needed for analysis 116 but are not obtainable in reality.

118 In appreciating the limitations of previous studies, Mccloughan (2004) devised a new concentration 119 model for the assessment of competition intensity in the British construction industry. Because of the 120 British-specific statistics variables, Mccloughan’s approach may not fully apply to other construction 121 industries such as the Chinese construction industry. A recent study by Ye (2009) established a causal- 
122 sequential coordinate system for measuring competition intensity in the construction market. Nonetheless, 123 the correlation between the two-dimensional factors was not addressed explicitly, which undermines the 124 usefulness of the model. There are some other measures such as consumer's travelling cost (Boone 2001), 125 price cost margins (Flath 2011), persistence of firm profitability (Jiang and Kattuman 2010), and residual 126 demand elasticity (Goldberg and Knetter 1999) for potential application in construction. Whilst deserving 127 attention, these measures have likewise limitation in application, as they were based on homogeneous 128 business rather than construction, which is substantially unique, one-off, and heterogeneous.

\section{Research gap}

While there lacks sufficient data to adopt the absolute concentration approaches, scholars are apt for the relative concentration approaches. Nevertheless, in many developing countries (e.g., China), data for calculating relative concentration indices of construction markets are not released until several years later. As a consequence, the competition situation of construction market is very hard to inform in a timely fashion to support the development of bidding strategies and industrial policies. It is very important in this content to identify alternative methods that can complement the relative approaches. This study aims to propose a new approach to improve the measurement of competition intensity in the construction market. The remainder of the paper is structured as follows. The theory of discriminant analysis is discussed in Section 2, providing a solid grounding for model development in the study. The discussion

141 leads to the establishment of multivariate discriminant functions as addressed in Section 3. Using the 142 empirical data collected from China, the developed functions are demonstrated in Section 4. Section 5 discusses the research findings and draws conclusions. 
147 Competition intensity is a relative term that reflects the level of rivalry within a given market 148 environment (Ramaswamy and Renforth 1996). The relativity is usually presented by making comparison 149 between different markets over a period of time or between different periods of time for a same 150 construction market (Ye et al., 2009). This relativity attribute suggests that the intensity of competition in 151 an observed market can be indicated by situating it into a set of markets that have competition features in 152 common. In light of the work by Kim et al. (2008), the technique of discriminant analysis (DA) was 153 therefore adopted for model development in the study. DA is a useful approach for classifying a set of 154 observations into predefined groups. Dating back to the 1920s, this approach has deserved much attention 155 in the areas of biology, business, education, engineering and psychology (Huberty and Olejnik 2006). DA 156 plays two roles in the study. One is for descriptive discriminant analysis (DDA), which elaborates how 157 well the selected variables separate a set of observations into groups and which specific latent variables 158 (discriminant functions) can provide the most suitable group discrimination. The other is for predictive 159 discriminant analysis (PDA), which focuses on the prediction of group membership. PDA and DDA 160 variables are interchangeable. Predictor variables in PDA (independent variables) are response variables 161 in DDA (dependent variables), while PDA's criterion variables (dependent variables) are DDA's 162 grouping variables (independent variables).

164 Multivariate discriminant analysis (MDA) is a typical DA technique to predict which group $(Y)$ an 165 observation belongs to using linear composites of predictor variables (X) (Lam et al. 2001). MDA has 166 become popular in the discipline of industrial economics, as it yields pragmatic solutions to many 167 industrial problems (Cabahug et al. 2004). The key procedure of MDA is to establish discriminant 
168 functions, where scores of the predictor variables are weighted up (Ary et al. 1990). MDA results in the 169 establishment of multivariate discriminant function (MDF) which is in general expressed as Equation 1. 170 The parameters of Equation 1 can be quantified using a set of observations that have been categorized 171 into some known groups $(Y)$.

172

$173 Y=f(x)=\alpha_{1} x_{1}+\alpha_{2} x_{2}+\alpha_{3} x_{3}+\ldots+\alpha_{n} x_{n}+\delta$

175 Where $Y$ is the response variable, $x_{n}$ is the predictor variables, $a_{n}$ is discriminant coefficients for variables $176 x_{n}$, and $\delta$ is a constant.

178 MDA seems to be multidimensional scaling (MDS) or multivariate analysis of variance (MANOVA). In 179 effect, they differ from each other. MDS contains a series of techniques used to identify key dimensions 180 of objects, while MANOVA is to determine whether multiple levels of independent variables on their 181 own or in combination with one another have effects on the dependent variables. By contrast, MDA is 182 more suitable for the study for two main reasons. First, multivariate discriminant function (Equation 1) 183 can detect the group membership of new observations. This prediction functions satisfies the research 184 purpose, while it is beyond the capacity of MDS and MANOVA. Second, to ensure that any statistically 185 insignificant variables are eliminated, a stepwise procedure is usually followed. Variables included in a 186 final MDF are thus not always the originally recognized ones. As such, different markets may have 187 different MDFs composed of different variables, despite that they have model structure in common. This 188 suggests that MDA be a better way to mirror flexibly the different combined effects of market powers on 189 competition intensity. 


\section{Predictor variables}

Competition intensity has been studied for long time with a large number of resultant publications in the area of industrial economics. Through extensive literature review, Ye (2009) identified more than 105

197 technical papers that address the subject of competition intensity, and 55 of them are concerned with the 198 factors of competition intensity. Using the method of content analysis on the 55 publications, Ye (2009) 199 unveiled a set of key indicators of competition intensity, namely business diversity (BD), market entry 200 barriers (MEB), market growth (MG), market size (MS), market share distribution (MSD), profitability 201 (PT), technical efficiency (TE), and average wage (WG). As the literature review is based on a thorough 202 analysis and detailed discussion in the construction context, the derived indicators were accepted as 203 predictor variables of MDF in the study. The determination of these variables concurs with previous 204 studies on that to ensure effective MDA reliability, the number of predictor variables should be 205 manipulated to be between 8 and 10 (Guo 2002). For simplicity, these variables are discussed as follows.

207 Business diversity (BD)

208 Business diversity means the heterogeneity of individual businesses in a market. Those construction 209 firms which have similar competitive strengths will compete strongly for common business, especially 210 when they are identical in either size or portfolio of investment. Therefore, a low degree of business 211 diversity can indicate intense competition in the market. In turn, fiercer competition in the market propels 212 firms to explore other opportunities. For instance, robust competition in the Chinese construction market 
213 has forced contractors to diversify business structures to escape from the previously narrow competition 214 (Wang 2004).

216 Market entry barriers (MEB)

217 Competition in a market consists of two parts - existing competition among the incumbents and potential 218 competition posed by new entrants (Porter 1980). Market entry barriers, such as economy of scale, 219 product differentiation, capital requirement, access requirement and government policy, put obstacles to 220 potential entrants into a new market (Bain 1956; Porter 1985). Potential competition is therefore 221 determined by market entry barriers. Previous studies have acknowledged the presence of market entry 222 barriers in the construction industry, and found them similar to other industries (Gruneberg and Ive 2000; 223 Ofori 1990). Higher entry barriers inhibit the entrance of new competitors significantly, and thereby 224 lower the intensity of potential competition. On the other hand, lower entry barriers facilitate the entrance 225 of new firms, giving rise to an increase in the number of firms as well as competition intensity.

Market growth (MG)

228 Market growth means the speed of market expansion. George (1967) pointed out that industry growth 229 decreases the level of competition intensity. This is because the existing competition in a market erodes 230 with the expansion of market volume which releases more spaces for incumbents to survive (Owen 1971). 231 However, there are different opinions. Baumol (1962) argued that rapid growth of an industry encourages 232 potential entrants, strengthening business competition as a result. Such point of view has been echoed by 233 other researchers (for example, Nelson 1960; Shepherd 1964) stating that a growing market will become 234 less concentrated and will have ascending intensity of competition. 
237 Market size is an important factor that firms take into account when launching a new product/service 238 program. A larger market size generates more business opportunities and the business competition can be 239 lessened accordingly. However, Mueller and Hamm (1974) claimed that market size has minor impact on 240 competition intensity if market demand is equivalent to supply. In effect, the impact of market size on 241 competition intensity depends on whether a variation in market size can render competition pressures 242 onto existing competitors. Therefore, a larger industry size causes business competition to intensify as the 243 entry barriers become lower (Bain 1956).

Market share distribution (MSD)

246 Business competition brings change to the distribution of market shares. Specifically, the distribution of 247 market shares will be concentrated if the market is dominated by a few firms. In reverse, market share 248 distribution will be more even if the existing competitors have equivalent market powers over product 249 prices. Market share distribution, therefore, may be a useful indicator of intensity of competition (Davies 250 and Geroski 1997; Ye et al. 2009). A more outspread distribution of market share means acuter 251 competition in the market (Alexander 2001).

253 Profitability (PT)

254 Profitability is a principal indicator of business performance and bears a direct relationship with the 255 intensity of competition. It seems that previous studies have not agreed with each other on the effect of 256 business competition on profitability. While intensive competition results in low profitability (Porter 257 1980), the study by Neumann et al. (1985) implied a loose relationship between profitability and 258 competition intensity. By contrast, Bain $(1951,1956)$ opined that a market moving towards a highly 
concentrated structure (little competition) is accompanied by a higher level of profitability. Similarly, the 260 studies by both Chiang et al. (2004) and McCloughan (2004) demonstrated that profitability in a market 261 with little competition is higher than that in those markets with intense competition.

263 Technical efficiency (TE)

264 Technical efficiency exhibits the utilization of technical resources in an industry. Primeaux (1977) 265 revealed that product cost can be decreased by increasing technical efficiency in response to market 266 competition, indicating that technical efficiency is an indicator of the intensity of competition. The work 267 by Ramaswamy and Renforth (1996) shows that a market with intensive competition urges firms to 268 improve technical efficiency continually.

270 Average wage (WG)

271 Cutting labor costs is an effective way for business to keep production cost as low as possible in reaction 272 to market competition (Ramaswamy and Renforth 1996; Bradburd et al. 1991). Nonetheless, this may not 273 be generalized in the construction context. Given a labor shortage, competition for labor resources will be 274 robust and labor costs will increase subsequently. It has been the norm that that employers tend to 275 improve staff strengths by reducing the number of less skilled employees while retaining good quality 276 staff who normally get more payment. Therefore, a higher level of competition increases the average 277 wage among competing firms.

\section{Criterion variables}


281 The classification cut-off points in previous studies usually follow rules of a thumb. For instance, a five 282 point category scale was appreciated effective in the studies by both Cabahug et al. (2004) and Kim et al. 283 (2008) to classify research objects into several groups. In a same way, this study adopted the CR 284 approach ( $\mathrm{n}=4,8,12$, etc.), which refers to the total amount of market shares of the largest $n$ firms, to 285 indicate the intensity of competition. As a major relative concentration measure, $\mathrm{CR}_{\mathrm{n}}$ is derivable and the 286 variable $n$ normally depends on the availability of data. As discussed earlier, although $\mathrm{CR}_{\mathrm{n}}$ is not ideal to 287 present the powers of all businesses in a market, it is practicable for the study to predefine the group 288 memberships of observed construction markets. In line with the availability of data and its widely 289 accepted criteria, $\mathrm{CR}_{4}$ was thus employed in the study.

291 Basically, the larger the $\mathrm{CR}_{4}$ index, the lower the competition intensity. To ascertain effective 292 classification, high, average and low levels of competition intensity are coded with an ordinal number $i$ 293 (criterion variables, $i=1,2,3$ ) respectively, each being defined in Equation 2, provided that $294 C_{1}<C_{2}<C_{3}$,

$$
f(x)=\left\{\begin{array}{l}
1 \text { (Group 1), if } C R 4 \leq C_{1}, \text { strong competition } \\
2 \text { (Group 2), if } C_{1}<C R 4 \leq C_{2}, \text { mod ernate competition } \\
3(\text { Group } 3), \text { if } C R 4>C_{3}, \text { low competition }
\end{array}\right.
$$

298 The criteria stated in Equation 2 serve to measure the intensity of construction business competition at 299 intervals. The intervals have been indicated in previous studies. Shepherd (1982) pointed out four types 300 of market structures, namely competition $\left(\mathrm{CR}_{4}<60 \%\right)$, oligopoly $\left(\mathrm{CR}_{4}>60 \%\right)$, dominant firm $301\left(50 \%<\mathrm{CR}_{4}<90 \%\right)$ and monopoly $\left(\mathrm{CR}_{4}\right.$ at or near $\left.100 \%\right)$. Using $\mathrm{CR}_{4}$ coefficients, Oster (1999) illustrated 302 competition cases with highly concentrated oligopoly $\left(0.75<\mathrm{CR}_{4}<1.00\right)$, moderately concentrated 
303 oligopoly $\left(0.50<\mathrm{CR}_{4}<0.749\right)$, oligopoly $\left(0.25<\mathrm{CR}_{4}<0.499\right)$, and atomism $(0.00-0.249)$. Nevertheless, as 304 reported by McClough (2004) and Ye et al. (2009), the construction market is fragmented, and $\mathrm{CR}_{4}$ 305 coefficients in construction are usually numerically very small. As such, a small change in $\mathrm{CR}_{4}$ numerical 306 value may not mirror effectively a small movement in the level of market competition. For instance, 307 according to Wang's (2004) calculation, CR $_{4}$ indices for those construction markets of China (1996), US 308 (1997), UK (1999) and Japan (1999) are 0.63, 3.23, 8.65 and 3.30 respectively, indicating minor 309 difference between countries in the globe. Therefore, the values of $C_{1}, C_{2}$ and $C_{3}$ in Equation 2 shall be 310 adjusted to reflect the characteristics of construction industries to ascertain that markets are grouped 311 appropriately.

\section{Discriminant functions}

315 Taking account of the predictor variables, Equation 1 is rewritten into the following multivariate 316 discriminant function (MDF):

$f(x)=\alpha_{1} x_{B D}+\alpha_{2} x_{M E B}+\alpha_{3} x_{M G}+\alpha_{4} x_{M S}+\alpha_{5} x_{M S D}+\alpha_{6} x_{P T}+\alpha_{7} x_{T E}+\alpha_{8} x_{W G}+\delta$

320 The relationships between competition intensity and predictor variables, as discussed in Section 3.1, are 321 summarized in Table 1. Of the relationships, the variables MEB, MG, and PT have negative relationships 322 with competition intensity, while the remaining variables are positively related. 
326 The predictor variables assume different units in practice. Since competition intensity is a relative 327 measure, the values of all the variables are normalized into relative values. Comparing $m$ markets for 328 relative competition intensity, the normalization of the independent variables is conducted as follows:

$X_{B D}=\left(B D-\min _{i=1}^{m} B D_{i}\right) /\left(\max _{i=1}^{m} B D_{i}-\operatorname{Min}_{i=1}^{m} B D_{i}\right)$

$X_{M E B}=\left(\underset{i=1}{m} M_{i} E B_{i}-M E B\right) /\left(\underset{i=1}{m} \operatorname{Max} \operatorname{MB}_{i}-\operatorname{Min}_{i=1}^{m} M E B_{i}\right)$

$X_{M G}=\left(\underset{i=1}{m} M_{i}-M G\right) /\left(\underset{i=1}{m a x} M G_{i}-M_{i=1}^{m} M G_{i}\right)$

$X_{M S}=\left(M S-M_{i=1}^{m} M S_{i}\right) /\left(\underset{i=1}{m} M S_{i}-M_{i=1}^{m} M S_{i}\right)$

$X_{M S D}=\left(M S D-M_{i=1}^{m} M S D_{i}\right) /\left(\underset{i=1}{m} M_{i} S D_{i}-M_{i=1}^{m} M_{i n}\right)$

$X_{P T}=\left(\underset{i=1}{m} P T_{i}-P T\right) /\left(\operatorname{Max}_{i=1}^{m} P T_{i}-\operatorname{Min}_{i=1}^{m} P T_{i}\right)$

$X_{T E}=\left(T E-\operatorname{Min}_{i=1}^{m} T E_{i}\right) /\left(\underset{i=1}{M a x} T E_{i}-\stackrel{m}{m i n}_{i=1} T E_{i}\right)$

$X_{W G}=\left(W G-M_{i=1}^{m} W G_{i}\right) /\left(M_{i=1}^{m} W G_{i}-M_{i=1}^{m} W G_{i}\right)$

340 increase in any variable of MEB, MG and PT means a decrease in competition intensity. On the other

341 hand, an increase in any of BD, MS, MSD, TE and WG reflects an increase in competition intensity. 342 Therefore, the discriminant model for measuring competition intensity is composed of Equations 2, 3 and 343 4. 
346 Empirical data from the Chinese construction industry were collated to demonstrate the efficiency and 347 effectiveness of the proposed MDFs (Equations 2, 3, and 4). To ensure the reliability of MDFs, the 348 sample size should be 10-20 times the number of variables, and the numbers of cases per group should 349 not be insignificantly different (Guo 2002). Therefore, China’s local construction industries were adopted 350 to ascertain sufficient samples.

352 The collected data are about construction firms' annual revenues larger than one hundred million RMB 353 for the years of 2002, 2003, 2005, 2006, and 2007. For Xizang, a north-west province of China, some 354 data were missed, and the province was thus excluded from the analysis. The samples for testing the 355 established MDFs are thirty provincial construction markets in China for five years as mentioned above. 356 In total, a set of 150 observations were documented, which satisfies the requirement of MDF 357 development. In addition, yearly statistical data published in the official website of National Statistics 358 Bureau (www.stats.gov.cn) were gathered to calculate all the variables as discussed below.

\section{Criterion variables}

362 Previous studies have demonstrated that the annual revenue of construction firms is used to calculate $\mathrm{CR}_{4}$ 363 for criterion variables (Ye et al. 2009). $\mathrm{CR}_{4}$ indices were calculated per local market per year, and the 364150 markets were then grouped into three in accordance with Equation 2. Comparing with the U.S., Li et 365 al. (2002) disclosed that China's construction industry has very small Gini coefficients, suggesting that 366 construction firms are unable to differentiate effectively in terms of company size. Kang and Zhang 367 (2008) revealed that the construction market is non-concentrated, and each firm has negligible market 
power. These studies agree with each other on the segmentation of the Chinese construction market.

369 Therefore, Equation 2 was re-expressed as follows to meet the segmentation features of China's 370 construction market.

$f(x)=\left\{\begin{array}{l}1 \text { (Group } 1), \text { if } C R 4 \leq 10 \%, \text { highly competitive } \\ 2 \text { (Group } 2), \text { if } 10 \%<C R 4 \leq 20 \%, \text { mod erately competitive } \\ 3 \text { (Group } 3), \text { if } C R 4>20 \%, \text { lowly competitive }\end{array}\right.$

Predictor variables

375

Predictor variables were quantified in accordance with the nature of the Chinese construction industry as described below.

Business diversity (BD): As reported by the Centre for Policy Research the Ministry of Construction (2007), construction firms in China supply diverse services such as construction, contract management, 381 architecture, consultancy, equipment leasing, and maintenance to the market. The structure of the income 382 composition of an individual firm, indicated by the proportion of auxiliary revenue to total business revenue, can mirror a firm's business distribution. Therefore, the auxiliary income proportion of construction firms was adopted as an indicator of business diversity in this study. The larger the average proportion, the higher the level of business diversity in the market.

Market entry barriers (MEB): In manufacturing industries, researchers have suggested measuring market entry barriers by plant capacity required for business operation in (Holtermann 1977; Farber 1981). However, the application of this method is less relevant in the construction industry. The 
possession of construction plant does not erect substantial barriers to potential entrants. Contractors

391 normally rent large items of plant only for the project period needed. Similarly, the average capital 392 among those existing firms registered to operate is employed to quantify market entry barriers. The larger 393 the average registered capital per firm, the higher the entry barrier.

Market growth (MG): Market growth is normally calculated by growth of market demand (Collins and Preston 1966). It is noted that market demand in the construction industry is hard to forecast exactly. For market. The higher the growth rate, the less intense the competition in the market.

Market size (MS): Market size can be measured from the perspective of either suppliers or consumers (Noh 2000; Mueller and Hamm 1974). Because of its close association with the magnitude of construction firms, construction market size was measured by the volume of construction works committed by all firms in a year. The larger the average volume of work in an area, the larger the market

Market share distribution (MSD): China's state-owned construction enterprises (CSCE) play leading 409 roles in local construction industries (Shen and Song 1998; Zou et al. 2007). They usually possess a 410 significant proportion of market share and dominate business competition in the industry. It was therefore 411 considered effective to measure MSD based on the market shares of CSCEs. 
413 Profitability (PT): Profitability refers to profit rate (Bonardi 2001). An average profit rate for 414 construction business is published by the National Statistics Bureau, and was thus adopted in this study.

416 Technical efficiency (TE): Wang (2004) suggested using the percentage of investment return on the 417 technical capital possessed by firms to measure technical efficiency. This percentage was similarly 418 adopted as a TE indicator in this study.

420 Average wage (WG): The level of average wage has been commonly measured either by hourly wage 421 rates or by annual wages (Haworth and Reuther 1978; Horowitz 1971). The total wage per person per 422 year was adopted as a WG indicator in this study.

\section{Descriptive discriminant functions}

426 Researchers have used computer software programs to conduct multivariate data analysis (Huberty and 427 Olejnik 2006). The Statistics Package for the Social Scientist (SPSS 15.0) was employed to model the 428 MDFs. Two discriminant functions (Function 1 and Function 2) are derived as indicated by the 429 eigenvalues and relative variances shown in Table 2. Total variance of the two functions is estimated at $430100 \%$, indicating that the classification of all construction markets can be explained adequately with the 431 two discriminant functions.

$433 \leq<$ Insert Table 2 here $>>$ 
435 As discussed above, the discriminant functions are preliminarily composed of eight predictor variables 436 (BD, MEB, MG, PT, MS, MSD, TE, and WG). With the application of a stepwise procedure embedded 437 in SPSS, three variables were found sufficient for the two functions (Table 3). It seems from Table 3 that 438 although the other criterion variables may influence market competition, a portfolio of three variables 439 (MSD, MS, PT) yielded sufficient discriminating results in relation to China's local construction markets.

$441 \leq$ Insert Table 3 here $>>$

443 The discriminant analysis derives two sets of standardized coefficients (Table 4). Based on these 444 coefficients, two discriminant scores, (f1, f2), for a local construction market can be detected. The 445 combined scores (f1, f2) enable the classification of a construction market by comparing the scores with 446 the group centroids shown in Table 5. Thereby, the group membership of a construction market can be 447 determined. As shown in Table 5, Group 1 has a negative mean for function 1, Group 2 has a negative 448 mean for function 2, and Group 3 has a positive mean for both functions 1 and 2.

$450 \leq<$ Insert Tables 4 \& 5 here $>>$

452 Territorial maps (Figure 1) were plotted in accordance with the combined scores (f1, f2). All construction 453 markets had values falling into the region bordered by the three groups. With the values determined for 454 the group centroids of 1, 2 and 3, it is seen that the three groups have mean values which are very close, 455 indicating the models for describing the competition status of local construction markets are similar.

$457 \leq<$ Insert Fiqure 1 here $>>$ 
459 Predictive discriminant functions

460

461 In accordance with the theory of discriminant analysis, predictive discriminant functions can be 462 established. The coefficients shown in Table 6 are rewritten as follows.

463

$f_{1}(X)=20.319 X_{M S}+11.980 X_{M S D}+9.046 X_{P T}-9.230$

$464 f_{2}(X)=14.569 X_{M S}+14.008 X_{M S D}+11.627 X_{P T}-9.388$

$f_{3}(X)=13.911 X_{M S}+20.698 X_{M S D}+13.267 X_{P T}-13.919$

465

466 Where $f_{i}(X) \quad(i=1,2,3)$ is the discriminant score for a given construction market in China.

467

468

$\leq<$ Insert Table 6 here $>>$

469

470 Discriminant scores for the yet to be analyzed construction markets can be determined using Equation 6.

471 Of the three scores derived, the group with the largest score categorizes a construction market. For 472 instance, for the Beijing construction market (2002):

473

474

$\mathrm{CR}_{4}=0.0690, \mathrm{X}_{\mathrm{MS}-\mathrm{bj}}=0.4611, \mathrm{X}_{\mathrm{MSD}-\mathrm{bj}}=0.5411$, and $\mathrm{X}_{\mathrm{PT}-\mathrm{bj}}=0.2803$

475

476 Then, according to Equation 6,

477

478

$f_{1}(X)=9.1571, f_{2}(X)=9.1501$, and $f_{3}(X)=8.1566$

479 
480 Because the largest discriminant score is $\mathrm{f}_{1}(\mathrm{X})$, the Beijing construction market (2002) can be classified 481 into Group 1. This accords with the CR4-based grouping, as the $\mathrm{CR}_{4}$ coefficient suggests the group 482 number of the market should be 1 according to Equation 5.

Validation

486 It is noted that predictions for future construction markets are outside the known observations from which 487 the discriminant model was built. To be sure at this stage that the derived model will suffice for future 488 predictions, measurement of the predictive accuracy of the mode is important. The accuracy is detected 489 by comparing the observed misclassifying rate to that expected by chance alone. The percentage of the 490 construction markets classified correctly is taken as an index of the effectiveness of the discriminant 491 function (Guo 2002). Results of the validation are shown in Table 7. it can be seen that the percentage of 492 cases correctly classified within groups 1, 2, and 3 are $71.9 \%, 65.5 \%$ and $57.1 \%$ respectively, indicating a 493 satisfactory degree of accuracy in the derived model.

$495 \leq$ <Insert Table 7 here $>>$

497 DISCUSSION

499 In this study, multivariate discriminant functions (MDFs) were developed as alternatives to traditional 500 approaches in measuring competition intensity in the construction context. The developed MDFs 501 encompass one criterion variable and eight predictor variables, namely business diversity, market entry 502 barriers, market growth, market size, market share distribution, profitability, technical efficiency, and 
average wage. Using the empirical data of China's construction industry, it was found that discriminant

504 analysis has the efficiency in measuring the intensity of competition in the construction market.

505 Specifically, of all the eight predictor variables, market size, market share distribution, and profitability 506 are identified as the elements of MDFs in China's local construction industries. These three predictor 507 variables were found effective to facilitate the classification of China's local construction markets into 508 three groups - high, moderate, and low level of intensive competition. Arguably, it could be the case that 509 other variables will eventually be key attributes in the discriminant model when examining other 510 construction markets. Different variables included in MDFs in different construction markets mirror the 511 changing combined effect of five market forces on competition intensity.

513 The MDFs contain the separation of construction markets into three groups (Groups 1, 2, and 3) in 514 accordance with the levels of competition intensity. Technically, while the separation is based on the 515 attributes of construction market, different criteria can be adopted by different researchers to satisfy 516 dissimilar intentions of discriminant analysis. Therefore, it is important to know what MDFs imply when 517 the criteria are laid down. In effect, the intensity of competition in two construction markets may not 518 differ significantly from each other if they are classified into a same group, while the difference will be 519 distinctive if the two markets fall into different groups. Therefore, it is implied that construction firms 520 take into account the group memberships of individual markets and make response to different market 521 situations in due manners. Reconsidering competition strategies is paramount when contractors are 522 transferring between different construction markets. For instance, in China, contractors moving from 523 Group 1 construction market to Group 2 will encounter more intensive competition, thus they have to 524 reevaluate competitive strategies accordingly. 
526 The MDFs can complement the traditional measures of competition intensity in construction context. In 527 previous studies, competition intensity in the construction market was usually measured through relative 528 concentration approaches. As discussed earlier in this study, the concentration-based measurement has 529 limited applications due to its onerous need for data input. Data about individual firms, the basis for the 530 concentration-based measurement, are difficult to collect in the vast majority of construction markets

531 worldwide. This impairs the effectiveness of the resultant concentration indices in reflecting competition 532 intensity in the construction market. The MDFs developed in this study are based on statistical data, 533 instead of detailed information about individual business, that are publicly ready in many countries. 534 Hence, the MDFs developed in the study are more applicable than traditional concentration methods. 535 Furthermore, with the assistance of MDFs, it is feasible to conduct a longitudinal analysis of a 536 construction market by taking into consideration the statistical data over a specific period of time. An 537 overview on the development of competition situations in a construction market can therefore be 538 examined.

540 Results of the MDFs indicate the group membership of a construction market, which states the interval of 541 competition intensity that the market belongs to, say $0 \%<\mathrm{CR}_{4}<10 \%$ (highly competitive). The interval 542 can be narrowed to improve the robustness of the measurement by giving more levels of criterion 543 variables of the MDFs. Therefore, the MDFs can aid construction professionals to understand the statuses 544 of market competition in due ways and results of the MDFs are informative to construction businesses 545 and the construction industry as a whole. With this knowledge of competition intensity, contractors are 546 more able to match business strategies to external market environments to ensure that their strategies are 547 competitive. In addition, construction clients can apply the MDFs to formulate more effective contractor 548 selection criteria during project tendering process, ensuring that an qualified contractor is selected. 
549 Furthermore, governments can apply the model to monitor various local construction markets from the 550 perspective of competition intensity and adopt proper leverage measures to improve resource deployment 551 efficiency across construction industries. While market players can gent benefits from the MDFs, more 552 efforts are necessitated to examine the nexus between competition intensity and competitiveness to guide 553 market players to make due response to the changing competition situations as indicated by the results of 554 discriminant model.

CONCLUSIONS

The construction market is characterized by fierce competition, requiring construction firms to carefully 559 identify the markets where they can find competitive advantages by understanding the competition 560 intensity between markets. Traditional approaches for analyzing market competition intensity have found 561 limitation in application. The discriminant model proposed in this study offers an alternative solution to 562 this limitation. The model consists of multivariate discriminant functions which quantify the intensity of 563 competition in a construction market by classifying the market into some predefined groups that have 564 known competition intensity. The values of the variables in these functions can be obtained from 565 statistical data which are commonly available. Therefore, the discriminant model is effectively applicable 566 in measuring the intensity of competition in the construction market. The application of the model helps 567 professionals in the construction industry understand competition situations in a construction market. 568 Thus, both competition strategies and policies can be formulated in due ways. The proposed model is a 569 development of the literature in examining competition intensity. Nevertheless, it is appreciated that the 570 empirical analysis of the proposed model is based on data which were collected from local construction 571 markets in China. Therefore, the applicability of the model in other construction contexts needs to be 572 further studied. 
REFERENCES

575

576 Aghion, P., Harris, P.H. and vickers, J. (2001). "Competition, Imitation and Growth with Step-by-Step Innovation." Review of Economic Studies 68(3): 467-423.

Alexander, A.M. (2001). The Role of Market Power in the Spatial Location of Industry, The University of Wyoming. Harcourt Jovanvich College.

Bajo, O. and Salas, R. (2002) Inequality Foundations of Concentration Measures: An Application to the Hannah-Kay Indices. Spanish Economic Review, 4(4), 311-16.

Bain, J.S. (1951). "Relation of Profit Rate to Industry Concentration in American Manufacturing 19361940." Quarterly Journal of Economics 65(3): 293-324.

Bain, J.S. (1956). Barriers to New Competition, Their Character and Consequences in Manufacturing Industries. Cambridge, Harvard University Press.

Baumol, W. (1962). "On the Theory of Expansion of the Firm." American Economic Review 52(5): 10781087.

Bishop, J.A., Chow, K.V. and Zeager, L.A. (2003). "Decomposing Lorenz and Concentration Curves." International Economic Review 44(3): 965-978.

594 Boone, J. (2001). "Intensity of Competition and the Incentive to Innovate." International Journal of 595 Industrial Organization 19(5): 705-726. 
596 Bradburd, R., Pugel, T. and Pugh, K. (1991). "Internal Rent Capture and the Profit-Concentration 597 Relation." Review of Economics and Statistics 73(3): 432-440.

598 Cabahug, R.R., Edwards, D.J. and Nicholas, J. (2004). "Classifying plant operator maintenance 599 proficiency: examining personal variables." Building Research and Information 32(2): 119-127.

600 Centre for Policy Research the Ministry of Construction (2007). Reform and Development - A Report on 601 Construction Industry and Market in China. Beijing, China Architecture \& Building Press.

602 Chiang, Y.H., Tang, B.S. and Leung, W.Y. (2001). "Market Structure of the Construction Industry in 603 Hong Kong." Construction Management and Economics 19(7): 675-687.

604 Collins, N.R. and Preston, L.E. (1966). "Concentration and Price-Cost Margins in Food Manufacturing 605 Industries." Journal of Industrial Economics 14(3): 226-242.

606 Davies, S.W. and Geroski, P.A. (1997). "Changes in Concentration, Turbulence, and the Dynamics of 607 Market Shares." Review of Economics and Statistics 79(3): 383-391.

608 Farber, S. (1981). "Buyer Market Structure and R\&D Effort: A Simultaneous Equations Model." The 609 Review of Economics and Statistics 63(3): 336-345.

610 Fedderke, J. and Szalontai, G. (2009). "Industry concentration in South African manufacturing industry: 611 Trends and consequences, 1972-96." Economic Modelling 26(1): 241-250.

612 Flanagan, R. and Norman, G. (1985). "Sealed Bid Auctions: An Application to the Building Industry." 613 Construction Management and Economics 3(2): 145-161.

614 Flath, D. (2011). "Industrial Concentration, Price-Cost Margins, and Innovation." Japan and the World 615 Economy 23(2): 129-139.

616 Fu, W.K., Drew, D.S. and Lo, H.P. (2003). "Competitiveness of Inexperienced and Experienced 617 Contractors in Bidding." Journal of Construction Engineering and Management 129(4): 388-395. 
618 George, K.D. (1967). "Changes in British Industrial Concentration 1951-1958." Journal of Industrial $619 \quad$ Economics 15(3): 200-211.

620 Goldberg, P.K. and Knetter, M.M. (1999). "Measuring the Intensity of Competition in Export Markets." $621 \quad$ Journal of International Economics 47(1): 27-60.

622 Greer, D.F. (1992). Industrial Organization and Public Policy. New York, Macmillan Publishing 623 Company.

624 Gruneberg, S.L. and Ive, G.J. (2000). The Economics of the Modern Construction Firm. Chippenham, 625 Great Britain, Antony Rowe Ltd.

626 Guo, W.T. (2002). SPSS 11.0 Advanced Guide to Statistical Data Analysis. Beijing, Press of Beijing 627 University of Posts and Telecommunications.

628 Hart, P.E. (1971). "Entropy and Other Measures of Concentration." The Journal of the Royal Statistical $629 \quad$ Society 138(1): 73-85.

630 Haworth, T.C. and Reuther, J.C. (1978). "Industrial Concentration and Interindustry Wage 631 Determination." Review of Economics and Statistics 60(1): 85-95.

632 Holtermann, S.E. (1977). "Market Structure and Economic Performance in U.K. Manufacturing 633 Industry." Journal of Industrial Economics 25(3): 177-193.

634 Horowitz, I. (1971). "An International Comparison of the International Effects of Concentration on 635 Industry Wages Investment, and Sales." Journal of Industrial Economics 19(2): 166-178.

636 Huberty, C.J. and Olejnik, S. (2006). Applied Manova and Discriminant Analysis, John Wiley \& Sons, 637 Inc., Hoboken, New Jersey.

638 Jiang, N. and Kattuman, P.A. (2010). "Intensity of Competition in China: Profitability Dynamics of 639 Chinese Listed Companies." Asia Pacific Business Review 16(3): 461-481. 
640 Kang, X. and Zhang, Y. (2008). "A Discussion on the Improvement of the Competitivenes Chinese 641 Construction Firms." Journal of Hubei Social Science 6(1): 73-75.

642 Kilpatrick, R.W. (1967). "the Choice among Alternative Measures of Industrial Concentration." Review $643 \quad$ of Economics and Statistics 49(2): 258-260.

644 Kim, D.Y., Han, S.H. and Kim, H. (2008). "Discriminant analysis for predicting ranges of cost variance 645 646 Asce 134(6): 398-410.

Kim, H.J. and Reinschmidt, K.F. (2006). "A Dynamic Competition Model for Construction Contractors." Construction Management and Economics 24(9): 955-965.

Lam, K.C., Runeson, G., Ng, S.T., Hu, T.S., Cheung, S.O. and Deng, Z.M. (2001). "Capital Budget Planning Practices of Building Contractors in Hong Kong." Construction Management and Economics 19(6): 569-576.

Lerner, A. (1934). "The Concept of Monopoly and the Measurement of Monopoly Power." Review of Economic studies 1: 157-175.

654 Li, X., Guan, K. and Li, Z. (2002). "The Structural Characteristics of Construction Industry in China." 655 Journal of Ha'er'bing Jianzhu University 35(5): 105-108.

656 Lo, W., Lin, C.L. and Yan, M.R. (2007). "Contractor's Opportunistic Bidding Behaviour and Equilibrium 657 Price Level in the Construction Market." Journal of Construction Engineering and Management 658 133(6): 409-416.

659 McCloughan, P. (2004). "Construction Sector Concentration: Evidence from Britain." Construction 660 Management and Economics 22(9): 979-999.

661 Mueller, W.F. and Hamm, L.G. (1974). "Trends in Industrial Market Concentration, 1947-1970." Review 662 of Economics and Statistics 56(4): 511-520. 
663 Nelson, R.L. (1960). "Market Growth, Company Diversification and Product Concentration, 1947-58." $664 \quad$ Journal of American Statistics Association 55(292): 640-649.

665 Neumann, M., Bobel, I. and Haid, A. (1985). " Domestic Concentration, Foreign Trade and Economic 666 Performance." International Journal of Industrial Organization 3(1): 1-19.

667 Newcombe, R. (1990). Construction Management 1: Organisation Systems. London: Mitchell.

668 Ngai, S.C., Drew, D.S., Lo, H.P. and Skitmore, M. (2002). "A Theoretical Framework for Determining 669 the Minimum Number of Bidders in Construction Bidding Competitions." Construction $670 \quad$ Management and Economics 20(6): 473-482.

671 Noh, G. (2000). The Effects of Competition and Resource on Firm Performance in Local Information 672 Service on the Web, Michigan State University.

673 Ofori, G. (1990). The Construction Industry, Aspects of its Economics and Management. Kent Ridge, 674 Singapore, Singapore University Press.

675 Oster, S.M. (1999). Modern Competitive Analysis. New York, Oxford University Press.

676 Owen, N. (1971). "Competition and Structural Change in Unconcentrated Industries." Journal of 677 Industrial Economics 19(2): 133-147.

678 Porter, M. (1980). Competitive Strategy: Techniques for Analysing Industries and Competitors. New $679 \quad$ York, Free Press.

680 Porter, M. (1985). Competitive Advantage. New York, Free Press.

681 Primeaux, W.J. (1977). "An Assessment of X-efficiency Gained through Competition." Review of 682 Economics and Statistics 59(1): 105-108.

683 Ramaswamy, K. and Renforth, W. (1996). "Competitive Intensity and Technical Efficiency in Public 684 685 Sector Firms: Evidence from India." International Journal of Public Sector Management 9(3): 417. 
Ruddock, L. (2002). "Measuring the Global Construction Industry: Improving the Quality of Data." Construction Management and Economics 20(7): 553-556.

Shen, L.Y. and Song, W.G. (1998). "Competitive Tendering Practice in Chinese Construction." Journal of Construction Engineering and Management 124(2): 155-161.

Shepherd, W.G. (1964). "Trends of Concentration in American Manufacturing Industries." Review of Economics and Statistics 46(2): 200-212.

Tan, W. (1989). "Sub-sector Fluctuations in Construction." Construction Management and Economics 7(1): 41-51.

Wang, D. (2004). The Chinese Construction Industry from the Perspective of Industrial Organization, North-western University.

Wang, J., Xu, Y. and Li, Z. (2009). "Research on Project Selection System of Pre-evaluation of Engineering Design Project Bidding." International Journal of Project Management 27(6): 584599.

Yang, H., Chan, A., Yeung, J. and Li, Q. (2012). "Concentration Effect on Construction Firms: Tests of Resource Partitioning Theory in Jiangsu Province (China) from 1989 to 2007." Journal of Construction Engineering and Management 138(1): 144-153.

Ye, K.H. (2009). Modelling Competition Intensity in Construction Market, The Hong Kong Polytechnic University. PhD.

Ye, K.H., Jiang, W.Y. and Shen, L.Y. (2008). "Project Competition Intensity (PCI) in the Construction Market: A Case Study in China." Construction Management and Economics 26(5): 463 - 470.

Ye, K.H., Lu, W.S. and Jiang, W.Y. (2009). "Concentration in the International Construction Market." Construction Management and Economics 27(12): 1197-1207. 
708 Zou, P.X.W., Fang, D., Wang, S. and Loosemore, M. (2007). "An Overview of the Chinese Construction 709 Market and Construction Management Practice." Journal of Technology Management in China 2(2): $163-176$.

711 
712

713 Table 1 I ndicators of competition intensity

\begin{tabular}{|l|l|l|l|l|l|l|l|l|}
\hline Competition intensity & $\uparrow$ & $\uparrow$ & $\uparrow$ & $\uparrow$ & $\uparrow$ & $\uparrow$ & $\uparrow$ & $\uparrow$ \\
\hline $\begin{array}{l}\text { Indicators/independent } \\
\text { variables }\end{array}$ & $\mathrm{BD} \uparrow$ & MEB $\downarrow$ & MG $\downarrow$ & MS $\uparrow$ & MSD $\uparrow$ & PT $\downarrow$ & TE $\uparrow$ & WG $\uparrow$ \\
\hline
\end{tabular}

714

715 
716

717 Table 2 Eigenvalue

\begin{tabular}{|l|l|l|l|l|}
\hline Function & Eigenvalue & $\%$ of Variance & Cumulative \% & $\begin{array}{l}\text { Canonical } \\
\text { Correlation }\end{array}$ \\
\hline 1 & $.818^{\mathrm{a}}$ & 92.4 & 92.4 & .671 \\
\hline 2 & $.067^{\mathrm{a}}$ & 7.6 & 100.0 & .251 \\
\hline
\end{tabular}

718 a. First 2 canonical discriminant functions were used in the analysis

719

720 
Table 3 Variables Entered/ Removed(a,b,c,d)

\begin{tabular}{|c|c|c|c|c|c|c|c|c|c|}
\hline \multirow[b]{3}{*}{ Step } & \multirow[b]{3}{*}{ Entered } & \multicolumn{8}{|c|}{ Wilks' Lambda } \\
\hline & & \multirow[b]{2}{*}{ Statistic } & \multirow[b]{2}{*}{ df1 } & \multirow[b]{2}{*}{$\mathrm{df} 2$} & \multirow[b]{2}{*}{ df3 } & \multicolumn{4}{|l|}{ Exact $F$} \\
\hline & & & & & & Statistic & df1 & df2 & Sig. \\
\hline 1 & MSD & .658 & 1 & 2 & 147.000 & 38.136 & 2 & 147.000 & .000 \\
\hline 2 & MS & .560 & 2 & 2 & 147.000 & 24.564 & 4 & 292.000 & .000 \\
\hline 3 & PT & .515 & 3 & 2 & 147.000 & 19.002 & 6 & 290.000 & .000 \\
\hline
\end{tabular}

723 At each step, the variable that minimizes the overall Wilks' Lambda is entered.

724 a Maximum number of steps is 16.

725 b Minimum partial $F$ to enter is 3.84 .

726 c Maximum partial $\mathrm{F}$ to remove is 2.71 .

d F level, tolerance, or VIN insufficient for further computation. 
731 Table 4 Standardized Canonical Discriminant Function Coefficients

\begin{tabular}{|l|l|l|}
\hline \multirow{2}{*}{} & \multicolumn{2}{|l|}{ Function } \\
\cline { 2 - 3 } & 1 & 2 \\
\hline MS & -.463 & .780 \\
\hline MSD & .657 & .761 \\
\hline PT & .414 & -.223 \\
\hline
\end{tabular}


Table 5 Functions at Group Centroids

\begin{tabular}{|l|l|l|}
\hline \multirow{2}{*}{$\mathrm{Cl}$} & \multicolumn{2}{|l|}{ Function } \\
\cline { 2 - 3 } & 1 & 2 \\
\hline 1 & -.983 & .168 \\
\hline 2 & .151 & -.321 \\
\hline 3 & 1.351 & .258 \\
\hline
\end{tabular}

736 Unstandardized canonical discriminant functions evaluated at group means 737 
739 Table 6 Classification Function Coefficients

\begin{tabular}{|l|l|l|l|}
\hline \multirow{2}{*}{} & \multicolumn{3}{|l|}{ Construction market group } \\
\cline { 2 - 4 } & 1 & 2 & 3 \\
\hline MS & 20.319 & 14.569 & 13.911 \\
\hline MSD & 11.980 & 14.008 & 20.698 \\
\hline PT & 9.046 & 11.627 & 13.267 \\
\hline (Constant) & -9.230 & -.9 .388 & -13.919 \\
\hline
\end{tabular}

740 Fisher's linear discriminant functions 
Table 7 Classification Results ${ }^{b, c}$

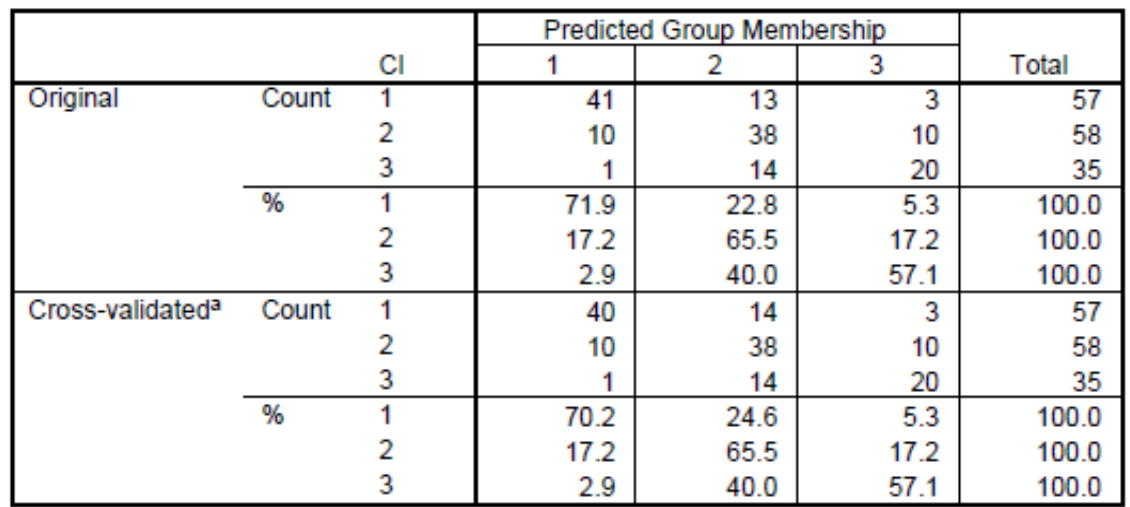

a. Cross validation is done only for those cases in the analysis. In cross validation, each case is classified by the functions derived from all cases other than that case.

b. $66.0 \%$ of original grouped cases correctly classified.

c. $65.3 \%$ of cross-validated grouped cases correctly classified. 


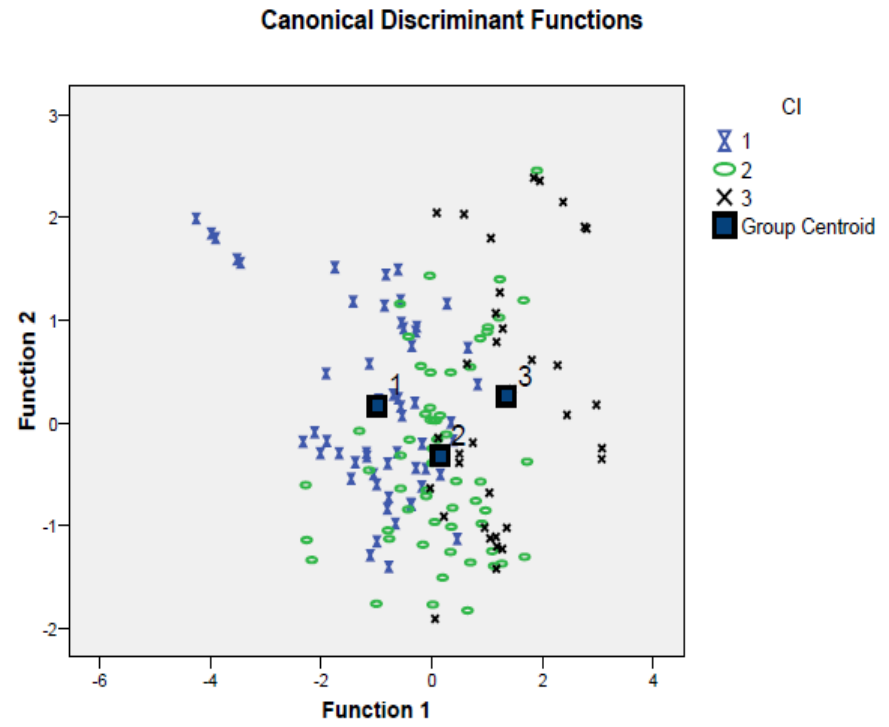

Figure 1 Canonical Discriminant Functions 